\title{
Influence of Subjective Knowledge, Objective Knowledge and Health Consciousness on Olive Oil Consumption-A Case Study
}

\author{
Adriana Gámbaro $^{1}$, Ana C. Ellis ${ }^{1}$, Víctor Prieto ${ }^{2}$ \\ ${ }^{1}$ Sensory Evaluation Laboratory, Food Science and Technology Department, School of Chemistry, Universidad de la República, \\ Montevideo, Uruguay; ${ }^{2}$ Department of Biometrics, Statistics and Computer Science, School of Agronomy, Universidad de la \\ República, Montevideo, Uruguay. \\ Email: agambaro@fq.edu.uy
}

Received December $20^{\text {th }}, 2012$; revised February $26^{\text {th }}, 2013$; accepted March $5^{\text {th }}, 2013$

Copyright (C) 2013 Adriana Gámbaro et al. This is an open access article distributed under the Creative Commons Attribution License, which permits unrestricted use, distribution, and reproduction in any medium, provided the original work is properly cited.

\begin{abstract}
Unlike the case in Mediterranean countries, where olive oil consumption is driven by habit or tradition, in a population where olive oil consumption rates are considerably low, it appears reasonable to suppose that the initial decision to buy a fairly expensive product - as is the case with olive oil in the Uruguayan market - may result from an individual's overall interest in health-related issues and/or their acquaintance with relevant nutritional properties of the particular product - in this case, olive oil. Consumer subjective and objective knowledge, interest in health-related issues, and demographic variables were studied for their potential relationship (explanatory capacity) with olive oil consumption frequency, using a sample of 256 inhabitants of Montevideo (Uruguay). Several of the studied variables were found to relate to olive oil consumption, such as subjective and objective knowledge, age, education level, marital status, and interest in health-related issues. Subjective knowledge was found to have the highest explanatory capacity. An increase in subjective knowledge is therefore expected to lead to an increase in consumption frequency among regular olive oil consumers, while it may also encourage less frequent or non-consumers to purchase olive oil and become acquainted with the product.
\end{abstract}

Keywords: Olive Oil; Subjective Knowledge; Objective Knowledge; Health Consciousness; Decision Trees

\section{Introduction}

Whereas olive oil has been known and used since ancient times, it was not long ago that its influence on the quality of life of consumers was acknowledged; neither has the importance of consumer preparation and education concerning the health benefits of olive oil been addressed until recently [1].

Extra-virgin olive oil has traditionally been used by European consumers, and it is a typical component of the Mediterranean diet. For example, average annual percapita olive oil consumption in Spain amounted to $12.9 \mathrm{~L}$ in 2004 , representing $2 \%$ of the total household expenditure [2]. In contrast, olive oil is a relatively new product in countries outside the Mediterranean basin, such as Uruguay. Being the least consumed oil in the Uruguayan market (corn, sunflower, high-oleic sunflower, soybean and rice bran oil), average annual per-capita consumption of olive oil in Uruguay amounted to as little as $0.2 \mathrm{~L}$ in
2007 [3]. However, olive oil production has increased significantly in the past 5 years and new, national brands have emerged in the Uruguayan market at an increasing pace.

As a result of abusive red meat consumption habits, the Uruguayan diet, based on an excessively high protein and fat intake, is far from being balanced [4]. However, a recent increase in health consciousness and nutritional awareness observed among one sector of the consumer market provides some potential for the adoption of a more balanced diet in Uruguay. Previous studies demonstrated that Uruguayan consumers perceive olive oil as different from other, locally available edible vegetable oils, describing it as a costly superior-quality gourmet oil associated with positive health effects that arouses positive feelings in consumers [5]. The effective design of a suitable strategy to encourage olive oil consumption among Uruguay's population should be based on the 
knowledge of major factors influencing olive oil consumption in Uruguay.

The relationship between consumer attitudes and behavior has been the subject of numerous studies in the fields of social psychology, marketing, and sensory evaluation. Consumer attitudes towards food and nutrition have been demonstrated to affect food consumption behavior to a considerable extent [6,7]. An essential factor influencing the consumption decision is an individual's knowledge concerning the available products. Two different aspects of such knowledge may be distinguished: objective knowledge, e.g., accurate information about the product stored in the consumer's memory for a long time period; and subjective knowledge, e.g., consumers' perception of the nature and extent of their own knowledge of a product [8]. Verbeke asserted that an adequate amount of knowledge based on reliable information is required for such information to have a favorable impact on an individual's choice of food. Based on this assumption, it is reasonable to suppose that subjective and objective knowledge concerning olive oil facts may be positively associated with a higher olive oil consumption frequency [6].

If actual and perceived knowledge were related [9], there should exist a direct relationship between objective and subjective knowledge. However, the degree of correspondence between objective and subjective knowledge has sometimes been reported not to be high $[8,10]$. More recently, highly diverse results concerning the two aspects of knowledge were reported in a recent metaanalysis [11].

Nonetheless, whereas excess self-confidence among consumers certainly accounts for a higher level of subjective knowledge, it is not necessarily associated with a significant amount of objective knowledge, as may be determined, for example, based on the percentage of correct answers to a list of specific questions. Several authors have found subjective knowledge to be a stronger driver of consumer behavior than objective knowledge $[12,13]$.

Because health improvement and maintenance interests might be major drivers for the purchase of olive oil, it is also essential to study the role of consumer interests in health-related issues in the process of purchasing olive oil. Among the Uruguayan population, where the olive oil consumption driver is unrelated to tradition or habit, it appears reasonable to suppose that the initial decision of purchasing a fairly costly product must be related to an overall attitude of concern regarding nutrition- and health-related issues. Likewise, it is reasonable to believe that a consumer willing to engage in healthy actions will have a more positive attitude toward olive oil consumption. Consumer willingness to engage in concrete actions concerning their own health is associated with an individual's willingness to engage in healthy actions, which may be evaluated as per the health consciousness questionnaire $[14,15]$.

In this paper, subjective and objective knowledge as well as that of general concern over health-related issues, in addition to other, demographic variables, were studied for their explanatory capacity for olive oil consumption frequency among one sample of Uruguayans.

\section{Materials and Methods}

\subsection{Data Collection}

The survey was carried out in Montevideo (Uruguay's capital) between March and September, 2011. 400 randomly selected inhabitants of diverse occupational backgrounds were provided with a self-response questionnaire, as a result of which, 256 completed questionnaires were made available.

Taking into account the areas where the participants were recruited, the sample was assumed to represent the general Uruguayan middle income groups.

The total sample comprised 152 females (59.4\%) and 104 males $(40.6 \%)$. Whereas the use of a non-probabilistic sampling method and the recruiting procedure utilized did not provide a statistically representative sample-thus, preventing the generalization of these results to the entire population living in Montevideo-a wide range of consumers was covered in terms of socio-demographic variables, as shown in Table 1. Participants were aged between 18 and 84, averaging $37.7(\mathrm{SD}=14.0)$ years of age. The sample was biased towards more highly educated individuals, probably as a result of an overall higher readiness of such individuals to participate in the survey.

\subsection{Measurements}

Olive oil consumption frequency was measured on a scale of 1 (never) through 7 (every day).

Objective knowledge was measured by means of 6 statements provided with optional answers (True; False; I do not know), based on the assumption that such 6 statements contained commonly known information among no less than one half of the population. 3 of those statements were false (Olive oil contains cholesterol; Olive oil is a source of saturated fat; Olive oil is a source of protein). The remaining 3 statements were true (The consumption of olive oil is important for the prevention of cardiovascular disease; Olive oil is a source of monounsaturated fatty acids; Olive oil is rich in antioxidants). In addition, the inclusion of an "I don't know" answer choice for each statement led to increased accuracy regarding an individual's effective knowledge about the 
Table 1. Socio-demographic sample characteristics.

\begin{tabular}{|c|c|c|}
\hline \multirow{2}{*}{ Gender } & Male & $104(40.6 \%)$ \\
\hline & Female & $152(59.4 \%)$ \\
\hline \multirow[b]{2}{*}{ Age (years) } & $18-35$ & $128(50 \%)$ \\
\hline & Older than 35 & $128(50 \%)$ \\
\hline \multirow{3}{*}{$\begin{array}{l}\text { Educational } \\
\text { level }\end{array}$} & $\begin{array}{l}\text { High school graduates } \\
\& \text { undergraduates }\end{array}$ & $25(9.8 \%)$ \\
\hline & $\begin{array}{l}\text { College graduates \& } \\
\text { undergraduates }\end{array}$ & $172(67.2 \%)$ \\
\hline & University graduates & $59(23.0 \%)$ \\
\hline \multirow{2}{*}{ Living situation } & Living with a partner & $119(46.5 \%)$ \\
\hline & Other living situation & $137(53.5 \%)$ \\
\hline \multirow{3}{*}{$\begin{array}{c}\text { Children in the } \\
\text { home }\end{array}$} & 0 & $175(68.4 \%)$ \\
\hline & 1 & $54(21.1 \%)$ \\
\hline & 2 to 4 & $27(10.5 \%)$ \\
\hline
\end{tabular}

product, avoiding the chance component associated with forcing an answer from the respondent. The number of correct answers $(0-6)$ provided by each respondent (OBJK) was used as an indicator of objective knowledge. (See Table 2).

Subjective knowledge of olive oil facts was measured by means of the following 3 statements: "Compared with other people, I know a great deal about olive oil", "People who know me consider me an olive oil expert" and "I know a great deal as to how to assess olive oil quality". Answers were provided on a scale of 1 through 7, (i.e., from "I completely disagree" to "I could not agree more"). This measurement method is consistent with those used in previous studies [13,16].

Health consciousness was measured by means of a list consisting of 15 items [17,18], assigning scores on a scale of 1 through 7, (i.e., from "I completely disagree" to "I could not agree more" for questions H1 to H5, H7, H12, H14 and H15; or from "It does not concern me at all" to "It really worries me" for questions H6 to H11 and H13) (see Table 3).

\subsection{Data Analysis}

The results of subjective knowledge and health-consciousness items were subject to an analysis of variance (ANOVA). The Tukey HSD test was performed to determine significant differences among those items relating to olive oil consumption frequency $(\mathrm{p} \leq 0.05)$.

A Pearson correlation analysis between olive oil consumption frequency and the quantitative variables was
Table 2. Percentage of correct answers for the objective knowledge items.

\begin{tabular}{lcc}
\hline & $\begin{array}{c}\text { Correct } \\
\text { statement }\end{array}$ & $\begin{array}{c}\text { \% of correct } \\
\text { answers }\end{array}$ \\
\hline $\begin{array}{l}\text { Olive oil contains cholesterol } \\
\begin{array}{l}\text { The consumption of olive oil } \\
\text { is important for the prevention } \\
\text { of cardiovascular disease }\end{array}\end{array}$ & YES & 52.0 \\
$\begin{array}{l}\text { Olive oil is a source of } \\
\text { monounsaturated fatty acids } \\
\begin{array}{l}\text { Olive oil is a source of } \\
\text { saturated fat }\end{array}\end{array}$ & YES & 18.8 \\
$\begin{array}{l}\text { Olive oil is a source of protein } \\
\text { Olive oil is rich in antioxidants }\end{array}$ & NO & 35.9 \\
\hline
\end{tabular}

used to determine the degree of linear association among such variables. An ANOVA was used to determine whether qualitative variables influenced olive oil consumption frequency. Significant differences among groups were determined by means of the Tukey HSD test ( $\mathrm{p} \leq$ $0.05)$.

To study the influence and hierarchization of those variables affecting olive-oil consumption frequency, a decision tree-based model was conveniently adjusted to enable the identification of patterns and classification rules within the database. The tree enables the explanation of $Y$ values based on the observed values of descriptive variables $(X)$ within a data set $D=(X, Y)$, where $X=$ $\left(X_{1}, \cdots, X_{k}\right)$ is a set of $k$ descriptive variables associated with the individual.

A hierarchized tree structure was defined as per the Decision Tree procedure used by SPSS software, based on the use of the CHAID algorithm to classify the sample into groups and subgroups in different hierarchies (one parent node and several child, grandchild nodes and so forth). The algorithm relies on the definition of significant partitions within the space of explanatory variables, i.e., Chi-square values in excess of a pre-set significance level of 0.05 , corrected as per the Bonferroni method. Whereas tree size depends on the number of significant hierarchical levels that may be identified within an $X$ variable, it was here restricted to within 4 levels for easy interpretation.

\section{Results and Discussion}

Olive oil consumption frequency scores among the sample did not differ considerably from the mean value (4.1 \pm 2.1 ). Figure 1 shows that olive oil consumption frequency was uniformly distributed among the 7 positions on the scale ( $1=$ never, $7=$ every day), i.e., the sample covered a wide range of consumption frequency values, thus representing low-, medium- or high-consumption 
Table 3. Subjective knowledge and health consciousness results.

\begin{tabular}{|c|c|}
\hline Item & Mean \pm SD \\
\hline \multicolumn{2}{|l|}{ Subjective knowledge items } \\
\hline Compared with other people, I know a great deal about olive oil & $3.2^{\mathrm{a}} \pm 1.8$ \\
\hline People who know me consider me an olive oil expert & $1.8^{\mathrm{b}} \pm 1.4$ \\
\hline I know a great deal as to how to assess olive oil quality & $2.1^{\mathrm{b}} \pm 1.5$ \\
\hline \multicolumn{2}{|l|}{ Health consciousness items } \\
\hline H1. My diet is well-balanced and healthy & $4.7^{\mathrm{c}} \pm 1.5$ \\
\hline H2. My health depends on the foods I consume & $5.9^{\mathrm{e}, \mathrm{f}} \pm 1.4$ \\
\hline H3. The amount of sugar I get in my food is important & $5.3^{\mathrm{d}} \pm 1.8$ \\
\hline H4. I have the impression that I sacrifice a lot for my health & $3.2^{\mathrm{a}} \pm 1.7$ \\
\hline H5. The amount of vitamins and minerals that I get in my food is important & $5.7^{\mathrm{e}, \mathrm{f}} \pm 1.4$ \\
\hline H6. I am concerned about the quantity of salt that I get in my food & $4.8^{\mathrm{c}} \pm 2.0$ \\
\hline H7. I think a good knowledge of how to eat healthily is important & $6.6^{g} \pm 0.9$ \\
\hline H8. I am concerned about the quantity of fat that I get in my food & $5.3^{\mathrm{d}} \pm 1.8$ \\
\hline H9. I am concerned about the quantity of salt that I get in my food & $5.4^{\mathrm{d}} \pm 1.8$ \\
\hline H10. I am concerned about the amount of cholesterol that I get in my food & $5.1^{\mathrm{d}} \pm 1.8$ \\
\hline H11. I am concerned about the quantity of fiber that I get in my food & $4.2^{\mathrm{b}} \pm 1.9$ \\
\hline H12. I continually ask myself whether something is good for me & $5.7^{\mathrm{e}} \pm 1.6$ \\
\hline H13. I consider that the deterioration of my health is very important & $5.1^{\mathrm{d}} \pm 1.8$ \\
\hline H14. I am prepared to sacrifice things for my health & $6.0^{\mathrm{f}} \pm 1.4$ \\
\hline H15. I think my health is influenced by my food & $4.6^{\mathrm{c}} \pm 1.8$ \\
\hline
\end{tabular}

Different superscripts in one column indicate significant differences among mean values according to the Tukey test ( $\mathrm{p}<0.05$ ).

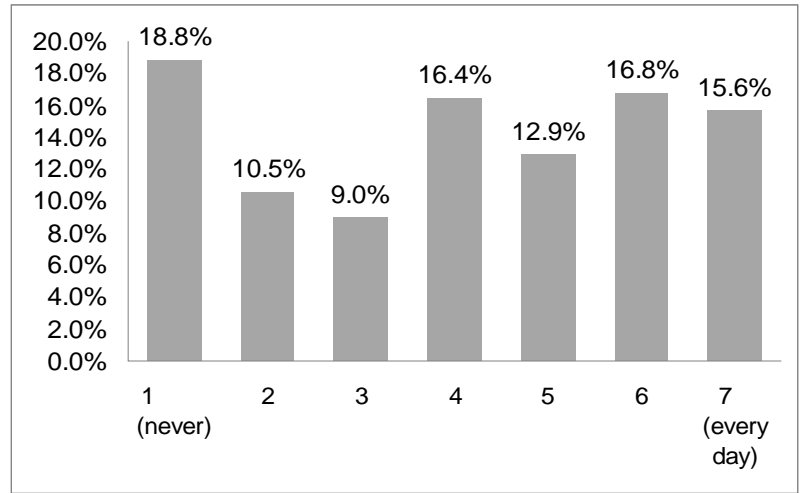

Figure 1. Olive oil consumption distribution among the sample.

individuals.

Table 2 shows the percentage of correct answers for each objective knowledge item.

The importance of olive oil consumption in the prevention of cardiovascular disease was the highest scoring item. However, the fact that $42.2 \%$ of the sample scored nil in this item appears to suggest that Uruguayans might have fairly little knowledge regarding the beneficial properties of olive oil. The cholesterol content item was also answered correctly by more than a half of the sample, which may be attributed to a number of recent marketing campaigns aiming at generating consumer awareness of the fact that vegetable oils do not contain cholesterol.

Those statements concerning the saturated fat and antioxidant content of olive oil were answered correctly by more than a third of the sample. As above, these terms are more commonly used among the population, and are usually used in marketing campaigns - albeit not specifically in association with olive oil.

The lowest percentage of correct answers was for those items concerning the protein and monounsaturated fatty acid (MUFA) content. The fact that $80 \%$ of the sample did not know that olive oil was not a source of protein indicates severe lack of knowledge concerning the nutritional composition of vegetable oils and sources of protein in general. Results obtained for the MUFA 
item, receiving incorrect answers from over $80 \%$ of the sample, may be ascribed to the highly technical nature of the term "monounsaturated fatty acid", with which the population in general is little familiarized.

The mean score obtained for OBJK (based on the number of correct answers) was $2.2(\mathrm{SD}=1.7)$, indicating that the sample were very little acquainted with facts regarding the composition and major health benefits of olive oil.

Mean scores and the corresponding standard deviations for subjective knowledge and health consciousness items are shown in Table 3.

Subjective knowledge scores were fairly low, indicating that the sample did not perceive themselves as olive oil connoisseurs. In a country where consumption rates are low, Uruguayans appear not to be confident about the amount of knowledge they possess concerning olive oil. The highest scores were for the "Compared with other people, I know a great deal about olive oil" item, reaching a mean value of barely 3.2. A strong linear correlation was found among the three items $(p<0.001)$, enabling the use of a subjective knowledge indicator (SUBK), defined as the average score for the three items $($ mean $=2.4 ; \mathrm{SD}=1.6)$.

OBJK correlated positively with SUBK (Pearson's correlation coefficient $r=0.51, p<0.001$ ), meaning that an individual's perceived knowledge of olive oil facts coincided with their actual knowledge of such facts, among the sample. The above finding differs from results reported for other food products $[8,11,16]$. Here, a stronger association between these indicators may be ascribed to low olive oil consumption rates in Uruguay, where olive oil is not consumed massively and it appears reasonable to suppose that those individuals who claim to have knowledge concerning olive oil facts must have attended courses, talks, tasting events, etc., where they may have gained some knowledge concerning its composition and associated health benefits.

Most of the health consciousness items scored high, showing an interest of the sample in certain heath-related issues. "I think a good knowledge of how to eat healthily is important" was the highest scoring item (6.6 maximum), showing that the sample was aware of the relationship between nutrition and health. The above was corroborated by the high scores associated with the "My health depends on the foods I consume" item (5.9). Also high scores were for "I am prepared to sacrifice things for my health", showing that the sample would consume food or, for example, engage in an economic endeavor, with the aim of attaining improved health.

Significantly low scores were for "I have the impresssion that I sacrifice a lot for my health" (3.2), suggesting that despite the sample's readiness to sacrifice things for the sake of their health, they do not do so in practice.

Table 4 shows the correlation between the different variables (OBJK, SUBK, health-related items, age) and olive oil consumption frequency. A correlation was considered significant when $\mathrm{p}<0.05$.

A highly significant correlation was found between olive oil consumption frequency and both objective and subjective knowledge. The above demonstrates the strong influence of actual and perceived knowledge of olive oil facts on an individual's olive oil consumption frequency. These results appear to suggest that an improved knowledge of olive oil facts may lead to an increase in olive oil consumption frequency.

A relationship was also found between olive oil consumption frequency and an individual's interest in health-related issues, a lesser interest in the product appearing to be associated with a lesser interest in healthrelated issues, particularly among those who considered that their diet was well-balanced and healthy who, in addition, assigned little importance to the sugar, vitamin, mineral, salt, cholesterol, fiber and fat intake in their diet. The above suggests a possible correlation between olive oil consumption frequency and the consumption of

Table 4. Correlation with olive oil consumption frequency.

\begin{tabular}{|c|c|c|}
\hline Item & Significance level (p) & Pearson's $r$ \\
\hline OBJK & $<0.001$ & 0.319 \\
\hline SUBK & $<0.001$ & 0.480 \\
\hline Age & 0.003 & 0.186 \\
\hline \multicolumn{3}{|c|}{ Health consciousness items } \\
\hline H1 & $<0.001$ & 0.263 \\
\hline $\mathrm{H} 2$ & 0.405 & 0.052 \\
\hline $\mathrm{H} 3$ & 0.004 & 0.182 \\
\hline $\mathrm{H} 4$ & 0.067 & 0.115 \\
\hline H5 & 0.028 & 0.137 \\
\hline H6 & 0.032 & 0.134 \\
\hline $\mathrm{H} 7$ & 0.789 & -0.017 \\
\hline $\mathrm{H} 8$ & 0.007 & 0.169 \\
\hline H9 & 0.208 & 0.079 \\
\hline $\mathrm{H} 10$ & 0.002 & 0.193 \\
\hline H11 & 0.001 & 0.202 \\
\hline H12 & 0.335 & 0.061 \\
\hline H13 & 0.466 & 0.046 \\
\hline H14 & 0.707 & 0.024 \\
\hline H15 & 0.158 & 0.089 \\
\hline
\end{tabular}


healthy foods in general, meaning that olive oil consumption may be associated with a healthier diet and lifestyle.

Age correlated significantly not only with olive oil consumption frequency but also $(\mathrm{p} \leq 0.05)$ with subjecttive and objective knowledge and health consciousness, suggesting that older-aged individuals may have more actual and perceived knowledge of olive oil facts and a higher interest in health-related issues; hence, the greater consumption frequency among these individuals. This is consistent with previous studies, where older-aged Uruguayans were reported to be better acquainted with nutritional facts and to have a higher consumption frequency of traditional Mediterranean foods [4].

An ANOVA was conducted on the olive oil consumption data, using gender, marital status, education level and number of children in the home as variation factors. No significant difference was found between males and females, $(p=0.824)$ or among groups associated with different numbers of children in the home $(p=0.716)$.

Marital status appears to have influenced olive oil consumption significantly $(\mathrm{p}<0.001)$. Individuals in "other living situation" reported a mean olive oil consumption of 3.6, a value significantly lower than for individuals "living with a partner" (4.6), appearing to suggest that olive oil consumption may be influenced by an individual's living condition. These results might reflect an apparent influence of a partner's interests, an individual's interest in their family consuming olive oil and/or an individual's own interest in consuming olive oil which is in turn shared with and adopted by those living in the home.

Education level appears to have influenced olive oil consumption significantly $(\mathrm{p}=0.003)$. "University graduates" reporting a mean consumption of 4.8, i.e., higher than for "high school graduates \& undergraduates" or "college graduates \& undergraduates" (3.2 and 4.0, respectively). These results are consistent with those of previous studies which suggest that a higher nutritional knowledge and a higher consumption frequency of healthy foods may be associated with a higher educational level among Uruguayans [4].

Figure 2 shows the resulting decision tree associated with frequent olive oil consumption, as a function of those variables of the greatest relevance in the process of group formation. The first partition was found as a function of SUBK, which had the highest explanatory capacity for olive oil consumption frequency among the studied variables. The sample was partitioned into four groups associated with different olive oil consumption frequency levels. A terminal node, the first child node from the right $(\mathrm{n}=23)$ represents those individuals associated with the highest scores in subjective knowledge (greater than 4.3) and the highest olive oil consumption frequency (mean of 6.0).

The first child node from the left $(n=63)$ represents those individuals with the lowest scores in subjective knowledge (below 1.0) and the lowest olive oil consumption frequency (mean of 2.3). This node is further partitioned as a function of scores obtained for "My diet is well-balanced and healthy". The first grandchild node from the left $(n=14)$ represents those individuals who disagree with the above statement and reported a lower olive oil consumption frequency (mean of 1.3), i.e., some individuals possessing the lowest levels of subjective knowledge and who consider that their diet is neither balanced nor healthy appear to be associated with the lowest olive oil consumption level.

An intermediate olive oil consumption frequency level is represented by two nodes: node 2, with SUBK levels ranging between 1 and $1.7(\mathrm{n}=46)$ and mean consumption frequency of 3.6; and node $3(n=124)$, with SUBK scores ranging between 1.7 and 4.3. This latter node is further partitioned as a function of education level, the first grandchild node from the right (node 8) representing those individuals reporting a higher education level (university graduates, $\mathrm{n}=30$ ) and a higher olive oil consumption frequency (mean of 5.5), among those represented in child node 3, of course. Representing those individuals reporting a lower education level, among those also represented in node 3 , node $7(\mathrm{n}=94)$ was further partitioned as a function of marital status. The terminal great-grandchild node $(\mathrm{n}=49)$, on the left, represents those individuals "living with a partner" reporting a higher olive oil consumption frequency (mean of 4.9). The great-grandchild node on the right $(n=45)$, representing, among those also represented in node 7 , those individuals in "other living situation", was further partitioned as a function of the "I am concerned about the quantity of fiber that I get in my food" (H11) item. On the left, a great-great-grandchild node $(n=30)$ associated with a higher consumption frequency (4.7) but relatively lower H11 scores (below 5.0); on the right, a greatgreat-grandchild node $(\mathrm{n}=15)$ associated with higher H11 scores but a lower olive oil consumption frequency (mean of 2.9).

In sum, those individuals with higher subjective knowledge of olive oil and health-related facts also reporting a higher education level or, else, living with a partner appear to have a higher olive oil consumption frequency. However, some individuals with high subjecttive knowledge of olive oil and health-related facts who live on their own and, in addition, do not appear to be interested in the fiber intake in their regular diet also tend to consume olive oil fairly regularly. In contrast, whereas objective knowledge correlated significantly with olive 
Influence of Subjective Knowledge, Objective Knowledge and Health Consciousness on Olive Oil Consumption-A Case Study

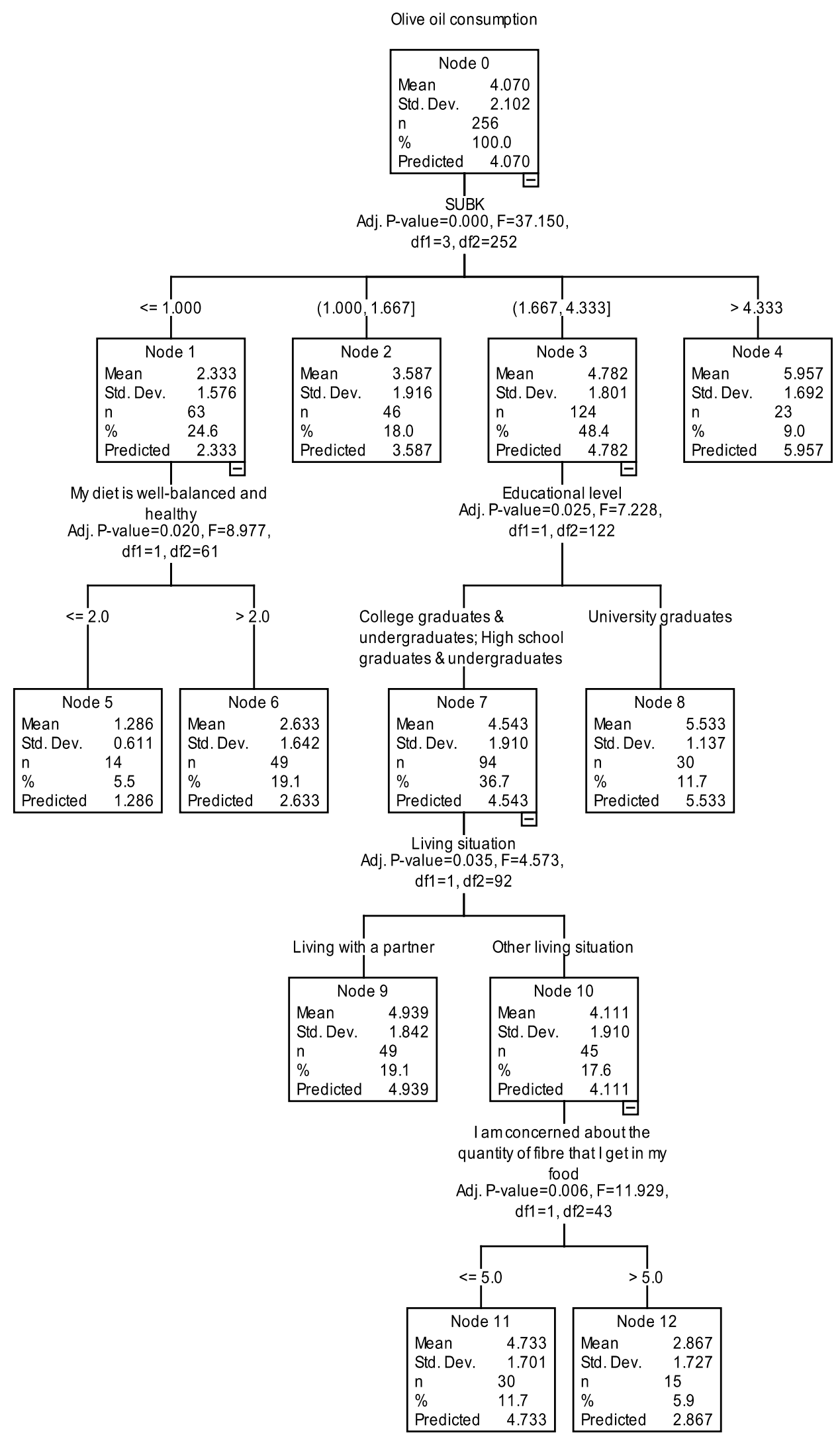

Figure 2. Decision tree. 
oil consumption, it did not have a significant relevance as a group forming variable at any hierarchical level.

\section{Conclusions}

Various factors have been shown to relate to olive oil consumption frequency among the sample, such as subjective and objective knowledge, age, education level, marital status and interest in health-related issues. Overall, participants were poorly informed concerning the composition and health benefits associated with olive oil.

A correlation found between olive oil consumption frequency and an individual's interest in health-related issues, including the sugar, vitamin, mineral, salt, cholesterol, fiber and fat intake in an individual's diet, suggests a possible relationship between olive oil consumption frequency and the consumption of healthy foods in general, meaning that olive oil consumption may be associated with a healthier diet and lifestyle.

Among the studied variables, subjective knowledge showed the greatest explanatory capacity for olive oil consumption frequency. These results need to be contemplated by policy developers and olive cultivators, meaning that subjective knowledge should be regarded as a major factor influencing olive oil consumption. Information and promotion campaigns should be targeted at stimulating consumers' confidence concerning their knowledge of what is good for their health. Increased subjecttive knowledge of olive oil facts may lead to an increase in consumption rates among regular consumers, while it may also encourage less frequent consumers to purchase and become acquainted with olive oil.

The effectiveness of communication efforts appears to depend not only on the amount of objective information that is conveyed to consumers but also on the resulting degree of confidence generated among consumers concerning their capacity to rely on information that is already available to them.

\section{REFERENCES}

[1] C. Delgado and J. X. Guinard, "How Do Consumer Hedonic Ratings for Extra Virgin Olive Oil Relate to Quality Ratings by Experts and Descriptive Analysis Ratings?" Food Quality and Preference, Vol. 22, No. 2, 2011, pp. 213-225. doi:10.1016/j.foodqual.2010.10.004

[2] ESPAÑA Ministerio de Agricultura and Pesca y Alimentación, "Estudio de Adecuación de la Oferta a la Demanda de los Aceites de Oliva Virgen y Virgen Extra Envasados," Ministerio de Agricultura, Pesca y Alimentación, Madrid, 2005.

[3] URUGUAY Presidencia de la República Oriental del Uruguay, "Oliva Uruguaya en Pleno Desarrollo y Expansión Productiva," Presidencia de la República Oriental del Uruguay, Montevideo, 2008.
[4] A. Gámbaro, L. Raggio, C. Dauber, A. C. Ellis and Z. Toribio, "Conocimientos Nutricionales y Frecuencia de Consumo de Alimentos: Un Caso de Estudio," Archivos Latinoamericanos de Nutrición, Vol. 61, No. 3, 2011, pp. 308-315.

[5] A. Gámbaro, C. Dauber , G. Ares and A. C. Ellis, "Studying Uruguayan Consumers' Perception of Vegetables Oils Using Word Association," Brazilian Journal of Food Technology, Special Issue, 2011, pp. 131-139. doi:10.4260/BJFT201114E000116

[6] W. Verbeke, "Impact of Communication on Consumers' Food Choices," Proceedings of the Nutrition Society, Vol. 67, No. 3, 2008, pp. 281-288. doi:10.1017/S0029665108007179

[7] I. Vermeir and W. Verbeke, "Sustainable Food Consumption: Exploring the Consumer 'Attitude-Behavioral Intention' Gap," Journal of Agricultural and Environmental Ethics, Vol. 19, No. 2, 2006, pp. 169-194. doi:10.1007/s10806-005-5485-3

[8] C. W. Park, D. L. Mothersbaugh and L. Feick, "Consumer Knowledge Assessment," Journal of Consumer Research, Vol. 21, No. 1, 1994, pp. 71-82. doi: $10.1086 / 209383$

[9] C. M. Radecki and J. Jaccard, "Perceptions of Knowledge, Actual Knowledge, and Information Search Behavior," Journal of Experimental Social Psychology, Vol. 31, No. 2, 1995, pp. 107-138. doi:10.1006/jesp.1995.1006

[10] J. W. Alba and J. W. Hutchinson, "Knowledge Calibration: What Consumers Know and What They Think They Know," Journal of Consumer Research, Vol. 27, No. 2, 2000, pp. 123-156. doi:10.1086/314317

[11] J. P. Carlson, L. H. Vincent, D. M. Hardesty and W. O. Bearden, "Objective and Subjective Knowledge Relationships: A Quantitative Analysis of Consumer Research Findings," Journal of Consumer Research, Vol. 35, No. 5, 2009, pp. 864-876. doi:10.1086/593688

[12] L. House, J. Lusk, W. B. Traill, M. Moore and C. Valli, "Objective and Subjective Knowledge: Impacts on Consumer Demand for Genetically Modified Foods in the United States and the European Union," AgBioForum, Vol. 7, No. 3, 2004, pp. 113-123.

[13] Z. Pieniak, W. Verbeke, K. Brunsø and S. O. Olsen, "Consumer Knowledge and Interest in Information about Fish," In: J. Luten, C. Jacobsen, K. Bekaert, A. Sæøbo and J. Oehlenschlager, Eds., Seafood Research from Fish to Dish: Quality, Safety and Processing of Wild and Farmed Fish, Wageningen Academic Publisher, Wageningen, 2006, pp. 229-241.

[14] P. A. M. Oude Ophuis, "Measuring Health Orientation and Health Consciousness as Determinants of Food Choice Behavior: Development and Implementation of Various attitudinal scales," In: G. J. Avlonitis, N. K. Papavasiliou and A. G. Kouremenos, Eds., Marketing Thought and Practice in the 1990s, EMAC XVIII, Athens School of Economics and Business, Athens, 1989, pp. 1723-1725.

[15] H. N. J. Schifferstein and P. A. M. Oude Ophuis, "HealthRelated Determinants of Organic Food Consumption in the Netherlands," Food Quality and Preference, Vol. 9, 
No. 3, 1998, pp. 119-133.

doi:10.1016/S0950-3293(97)00044-X

[16] Z. Pienak, J. Aertsens and W. Verbeke, "Subjective and Objective Knowledge as Determinants of Organic Vegetables Consumption," Food Quality and Preference, Vol. 21, No. 6, 2010, pp. 581-588. doi:10.1016/i.foodqual.2010.03.004

[17] R. Baixauli, A. Salvador, G. Hough and S. Fiszman, "How Information about Fiber (Traditional and Resistant Starch)
Influences Consumer Acceptance of Muffins," Food Quality and Preference, Vol. 19, No. 7, 2008, pp. 628-635. doi:10.1016/i.foodqual.2008.05.002

[18] V. S. Mialon, M. R. Clark, P. I. Leppard and D. N. Cox, "The Effect of Dietary Fiber Information on Consumer Responses to Breads and 'English' Muffins: A Crosscultural Study," Food Quality and Preference, Vol. 13, No. 1, 2002, pp. 1-12. doi:10.1016/S0950-3293(01)00051-9 